\title{
The Rights and Realities of War-affected Refugee And Asylum-Seeking Children and Youth in Québec: Making Children's Rights Meaningful
}

\author{
Myriam Denov \\ School of Social Work, McGill University \\ Natasha Blanchet-Cohen \\ Applied Human Science, Concordia University
}

\begin{abstract}
Each year, thousands of children enter Canada, fleeing from countries where there has been armed conflict. In Québec alone, between 1998 and 2007, eight of the top ten source countries for accepted refugees were war-affected nations, representing 34,838 people, including children. Yet, this group has been largely overlooked in Canadian research, policy and service provision. This article traces the lived realities and resettlement experiences of a sample of war-affected children and youth living in Québec who arrived accompanied by a parent or caregiver, alone as refugees, or without documented legal status, seeking asylum. Drawing upon in-depth interviews with 22 war-affected youth, the paper considers young people's perspectives on the experience of war and resettlement to Canada. The article examines the impact of the UNCRC on their lives in their countries of origin, in their resettlement to Canada, as well as Canada's role and obligations in meeting the needs and rights of this unique population. The article concludes with a discussion of the implications for policy and practice, particularly with regard to envisioning ways of better meeting the rights of war-affected children.
\end{abstract}

Keywords: UNCRC, Children, War, Resettlement, Québec, lived experiences 


\section{War-Affected Refugee And Asylum-Seeking Children And Youth In Québec: An Invisible Population}

Each year, thousands of children and youth enter Québec, fleeing from countries and communities in which there has been war and armed violence (Ministère de l'Immigration et des Communautés Culturelles, MICC, 2009). These refugee children are sometimes accompanied by a parent or caregiver and sometimes arrive alone as refugees, or without documented legal status, seeking asylum. In Québec, between 1998 and 2007, eight of the top ten source countries for accepted refugees were war-affected states including Afghanistan, Colombia, the Democratic Republic of Congo, India, Iran, Pakistan, Peru, and Sri Lanka, representing 34,838 people, including children (MICC, 2009). However, research on war-affected populations in Québec, particularly children, remains in its infancy, and our understanding of the wartime, flight and resettlement experiences of these children and youth is inadequate. The knowledge that we do have from other contexts has consistently shown that past exposure to the extreme violence of war presents significant risks to children's long-term psycho-social well-being (APA, 2010). While there is great variability in young people's experiences, their journeys to a new context and the conditions in which they find themselves as new arrivals, those displaced from war zones may endure significant trauma, stress, and adversity that can severely impact their functioning and development (Betancourt et al., 2010). Children and youth affected by war have often lived in societies where basic social structures and systems have been degraded or completely collapsed. In addition, the experience of flight from their country of origin may present additional threats to their safety, alongside the complexities of resettlement to a new context. Studies on war-affected refugee children in the United States have found that post-migration, these children continue to experience anxiety, depression and post-traumatic stress (Halcon et al., 2004; McCloskey et al., 1996). For children who make their way to Québec, war-related mental health distress may occur alongside poverty, discrimination, isolation, language barriers and difficulties in school (Denov \& Bryan, 2010).

Despite the many hardships that this group of children and youth may face, both in their countries of origin and upon resettlement to Québec, this population has been largely overlooked in provincial and national research, policy and service provision, particularly in discussions pertaining to rights. This article addresses this gap by examining the rights and realities of war- 
affected children and youth from a child rights perspective. We focus on Article 38 (4) and Article 39 of the United Nations Convention on the Rights of the Child (UNCRC), which are of particular relevance to wartime, post-war, and resettlement. Article 38 (4) outlines that:

In accordance with their obligations under international humanitarian law to protect the civilian population in armed conflicts, States Parties shall take all feasible measures to ensure protection and care of children who are affected by an armed conflict.

This Article establishes that children have the right to be protected during times of war and that governments must do everything they can to protect and care for children affected by war. In relation to the post-war and resettlement context, Article 39 articulates that:

States Parties shall take all appropriate measures to promote physical and psychological recovery and social reintegration of a child victim of: any form of neglect, exploitation, or abuse; torture or any other form of cruel, inhuman or degrading treatment or punishment; or armed conflicts. Such recovery and reintegration shall take place in an environment which fosters the health, self-respect and dignity of the child.

According to Article 39, once resettled in Canada, provincial and federal governments have an obligation to promote the physical and psychological recovery and social reintegration of children who have been affected by war.

In reality, what are the implications of Articles 38 (4) and 39 on the lives of war-affected youth both in their countries of origin and upon resettlement to Québec? How do they experience migration and resettlement in Québec? How do these youth perceive the available support in the education, and social service systems? How can understanding youth realities contribute to moving towards a more meaningful implementation of children's rights?

In this paper, we explore the direct experiences and perspectives of a group of waraffected children and youth living in Québec. As active rights holders, and consistent with childhood studies, we recognize children as subjects who contribute to society, shaped by time and space (Liebel, 2012). Young people's perspectives, knowledge, concerns, and needs on armed conflict and its impact are however largely invisible in scholarly discussions (Hart, 2008), 
and underplayed in international human rights law which often emphasizes the child as 'victim' and 'vulnerable' (Vandenhole, Parmentier \& Derluyn, 2011, p. 9). Reflecting conventional notions of power, and what is regarded as "expert" knowledge, children and youth are often talked about by researchers and policy makers, rather than talked to. Boyden \& De Berry (2004) have noted that information on war and its impact is largely drawn from adult informants, which has significant implications. They write:

It implies that children's insights have no relevance or scientific validity as compared with the expert knowledge and interpretive skills of the researcher. It suggests that children's testimony is unreliable and that children do not have the capacity to give a proper account of their lives....Children are thought to lack the maturity to hold and articulate valid views (p. 248).

Indeed, there is a compelling rationale to explore experiences of war, migration and resettlement that are grounded in the perspectives of the youth themselves - from the bottom-up. Moreover, it is increasingly recognized that programs and services need to be evaluated not by service-providers but by right-holders (Ben-Arieh, 2008). In light of this point, we draw upon the voices of 22 war-affected children and youth living in Québec to explore the realities and impact of war, migration and resettlement and their implication for rights. Based on the interviews and focus groups, this article critically examines the significance of Articles 38 (4) and 39 for these children and youth within their countries of origin and in their resettlement. The paper concludes with a discussion of the implications for policy and practice, particularly with regard to envisioning ways of better meeting the rights of war-affected children given Québec and Canada's role and obligations in meeting the needs and rights of this unique population of children.

\section{Methodology}

To examine the experiences of war-affected children and youth living in Québec, indepth interviews were conducted with 22 children and youth affected by war (11 male and 11 female) living in Montreal and St-Hyacinthe, a small-sized city in the outskirts of Montreal. The young people were recruited through the assistance of local settlement workers, social workers, 
as well as through snowball sampling techniques. Given our desire to ensure participants' overall safety and security during the research process, we aimed to include youth who were in some way along the "healing" journey. In this sense, participants were perceived as "leaders" by local social workers and settlement workers, who assisted in participant outreach. Following ethical approval, we also made sure that interviewees had a local support system in place. Interviews took place at community centres or in the office of the researchers and lasted between one and two hours.

To ensure that the views and perspectives of war-affected children and youth were appropriately captured (Blanchet-Cohen, 2013), six war-affected youth (aged 17-25) were advisors during the design phase of the research. These youth advisors were all from Colombia, and had sought refuge in Canada as a result of armed conflict, and had been living in Québec between two and five years. A group discussion was held with these youth that outlined the goals and objectives of the research, and that explained our desire to develop interview questions that were relevant to pose to potential research participants. The youth were then asked to participate in a group discussion that addressed the opportunities and challenges that they themselves had experienced when resettling in Québec. Following the discussion, the youth individually and collectively devised sample interview questions that they felt would be relevant and important to ask war-affected youth participants recently resettled to Québec. These youth consultants also offered critical feedback on our overall research objectives and provided direction in terms of appropriate methodologies emphasizing the importance that the interviewers "be present and ready to listen." A key contribution of the youth advisors was their emphasis on the importance of talking about their wartime past. One of the youth explained:

It is important to know the circumstances of youth prior to their arrival [in Canada] in order to understand what they may need. Some youth may seem to be functioning well on the outside but on the inside, they may have a lot of repressed emotions and feeling. Experiences lived [during war] are not forgotten and are therefore expressed in different ways.

The interview protocol, developed based on their feedback, explored young people's wartime lives and experiences in the context of their countries of origin, the impact and legacy of 
the war on their lives, both past and present, as well as the realities of flight and resettlement to Québec. The interviews also explored participants' sources of support and experiences with social and health services once in Québec, both formal and informal. In addition to interviews, two focus groups with war-affected youth were conducted to trace the diverse opportunities and challenges that they faced upon resettlement to Québec.

Participants in the interviews and focus groups were between the ages of 15 and 30 at the time of the interview/focus group, and had been living in Québec between six months and 12 years. Their countries of origin included Colombia, Democratic Republic of Congo, Nepal, Rwanda, Sierra Leone, Sri Lanka, Togo, and Zimbabwe and were carried out over a 10-month period, beginning in January 2013. Interviews were carried out in French, English or Spanish, depending upon participants' language preference. All interviews were audio-recorded with permission and subsequently transcribed.

Data were analyzed using a grounded theory approach, whereby knowledge is generated by an iterative process involving the continual sampling and analysis of qualitative data. Through inductive analysis of the data, researchers gain an understanding of the patterns that exist in the social world under study that are firmly grounded in the experiences of the individuals acting in it (Glaser \& Strauss, 1967). To facilitate data analysis, a conceptual coding tree was created with the assistance of HyperResearch - a qualitative analysis software.

\section{Youth Perspectives On War And The Decision To Flee: Rights, Violations and Survival.}

As voiced by the youth advisors, to understand current situations of resettlement, one needs to consider the past, and its impact, as well as the migration process. This is part of contextualizing childhood, recognizing that the profound violence and struggles war-affected children face on a daily basis may shape how they will experience and seek their rights. Below, we examine participants' narratives on the memories of war, and the moment of leaving their country of origin.

\section{Wartime Realities: "Even the Birds Weren't Singing"}

Children and youth interviewed for the research reported witnessing and/or directly experiencing severe and unimaginable violence and upheaval in their countries of origin. The 
following participants describe the context in which they lived, which was characterized by ongoing violence, insecurity, and poverty:

The soldiers took it on their own authority to come knocking at your door. If you're a woman or a lady, they don't care...If you are a mother, a "mommy" ...they say to your son: "Have sex with your mother." Stuff like that. And if you're the father: "Have sex with your little girl." But if you are the daughter, they just kill you, or they kill the mother. They massacre people....(Gilles)

Where there is war, there is no peace, there is no safety, there is no stability, so there are always problems, day and night. It affected a lot: it affected us physically, it affected us psychologically, it affected us morally, it affected us in every possible way...the disgust, not even feelings, to feel not at home, in your own country. It's just too much... We lived like that, we grew up like that, in constant peril, threats from left to right. (Ronaldo)

Etched in their memories, participants vividly recalled key wartime events and circumstances:

\footnotetext{
"There are certain things I can still remember. A seven-year-old child is not a baby." (Jasmine)
}

This male participant from DRC recalled the precise time of day the war began in his country, as well as the pervasive feelings of fear and insecurity:

It was around ...three in the afternoon. The weather, during the war, really, you can...you can also feel there is a difference. It was a clear sunny day, even the birds weren't singing. Even the sun wasn't...shining the way it should. (Gilles)

Although participants came from diverse contexts and circumstances, they recalled with surprising similarity what it meant to live in a state of constant fear as a result of armed conflict:

We were nearly captured, kidnapped. So we had to get out... The guerillas said: "If we can't find the mother, we'll kidnap the children, and the mother will come look for them, 
for sure." That's it...fear all the time...everyone was in danger. And then we had to split up at a friend's place. Thank goodness we had lots of networks... (Alina)

They did come after me. I was hiding...I stayed in the forest, [in the] bush for months, yeah two months, because I was hiding, so that they won't kill me. They had killed all my family members, and they were looking [for me]. Because, it's like, your neighbours, they know everybody at home. They know they have already killed this and that, this and that, and this one is remaining. Yeah, they knew I was still there, and they were looking for me... They don't want anyone to remain. So, like I think they had a list of people...They put a check [mark], this one is killed. This one is remaining, question mark. Where is this person? And they start searching for you. (Jasmine)

The glaring rights violations of the young people are revealed not only in the profound lack of protections provided to them during armed violence, but also in the significant losses of loved ones. The violent and senseless murders of family members and close friends profoundly marked participants' lives. These participants explained their tragedies:

I lost my entire family...I was born in a family of six kids. I was the fifth. I had a father and mother. I had a grandmother, my mother's mother. I had my aunt. I had three aunts, one uncle on my father's side. Then I had two aunts, one uncle on my mother's side. And, yeah, I lived happily. But, during the Rwandan genocide, they were all gone. I lost my entire family ...the entire family. Sisters, brothers, father, mother, grandparents, aunts, uncles. (Jasmine)

When I was four, my dad...I don't like to say: he got himself killed (s'est fait tuer). In French, that's how it is said, but I find it very strange. Because it sounds as if he was the one who got himself killed. Anyway...he was murdered when I was four years old. (Alina)

My father died in the war [in the Congo]; it was the war that killed my father, so you know I am a victim of that too... It's very hard. It is engraved, engraved in my heart. 
Sometimes it seems to me as if I must want to be a victim, but I don't want to, because his death was really inhumane, you know, burning someone with a grenade. When my father was killed, he was in church, praying... My mother and father are both dead. I was raised by my aunt, but my aunt also lost her husband and even her kids in the war of 2004. (Ronaldo)

There was the loss of my dad. So, actually, I always lived with my mom, dad, brothers and sisters, and then suddenly someone is missing. At some point you realize it, you tell yourself finally that the person is no longer there and will never be there... (Kimberly)

While Article 38 (4) of the UNCRC clearly articulates that governments must ensure the protection of children during times of war, participants' stories and reflections on their wartime pasts reveal the glaring lack of protection and the fundamental violations of their rights in multiples ways.

\section{Leaving Home: Flight \& Decision-Making}

Given the ongoing violence, wartime violations and threats of death, for participants, fleeing their countries of origin was a clear survival tactic and often occurred during times of intense fighting, stress, and instability. For the majority of participants (15), there was no time for them or their families to reflect on where they were going or what the future would hold they simply had to flee for their safety. This participant from DRC explains:

So the UN was there to help people, collect up children in the streets or women who had been assaulted a little, to take them...I don't know where. And we saw that the $\mathrm{UN}$ is there to help people, to gather people up... So that's it, if, during the wars, we had wanted to. If we die, we die. So we went too. We got into their little car...their truck. And we left. (Gilles)

In other cases, the decision to flee their country of origin was made by parents or adult caregivers on behalf of the child. In these situations, the young person was excluded from the decision- 
making process. The lack of participation in that decision-making continued to be a source of resentment and ambivalence:

To be honest, I never wanted to come to Canada... My parents ended up sending me away...they felt there was no hope for me staying and becoming part of the system or becoming part of something which would probably lead me to becoming arrested or tortured, or one of those things. That's why I ended up coming to Canada and seeking political asylum on those grounds...it was absolutely not [my decision]... There is still mixed feelings. Coming and seeking political asylum in Canada, there's still mixed feelings. (Andy)

In contrast, several (9) participants actively chose to leave their countries of origin alone and unaccompanied. These participants appeared to thoughtfully assess their situations and decided, often after a great deal of reflection, that the best option was to flee. These participants all mentioned a concern with security in making their decision:

The reason why I left is because Rwanda was a peaceful country. Like, at the moment I left, there was no longer genocide, no people killing others. But [it was] the reconciliation thing. The president or the government wanted people to reconcile. People who killed to reconcile with the families they killed. So, I don't know whether there was a chance. I met the person that killed my father. And, yeah, like, he told us the way he killed him. Like, they gave us details which was so scary. I couldn't stand that. And so, I was afraid. Very afraid. I wouldn't sleep, I was like: tomorrow he will come and kill me... After that, I said, I can't stay. He will kill me...To me, it was just like, I know there [in Canada], the country's secure. So, no one will kill me. That's what I was thinking. If no one will kill me there, I will be alone, independent...I was looking for security. (Jasmine)

Why did I decide to come to Canada? For a better future, of course. To be somewhere secure with my children and live a better life without fear. (Tamara) 
It was for my security, that's it. Simply for my security. Because what made me leave my home in my country, it was the insecurity, the instability that made me leave. (Ronaldo)

Once the decision was made, participants faced profound dangers and challenges during flight. This participant from Rwanda recalls:

[I left my country] by car. But when I say by car it's like when you open up a cup of sardines, you see how the sardines stick together, that is how we were.... Even when we reached the border, I can still remember we had our stuff ... We wanted to climb on [a raft] to cross a river, but everyone needed to escape from the shooting... So, the first group I can remember climbed on it and it sank with them and people died. We climbed on the other and, as God would have it, we made it. (Jasmine)

Whether fleeing alone or with family members, several participants (7) did not go directly to Canada, but were displaced to neighbouring countries. However, war and/or civil unrest often forced them to flee those contexts. As an example, this participant fled the war in the DRC and was displaced to Burundi, Kenya, and then Malawi before coming in Canada. He explains the challenges associated with repeated flight:

It also affected us to say that...to leave our country, to go to another country. To take up different cultures, to begin to face different problems... as if the problems that we had survived... So I can say that there, too, in Gatumba, there was a massacre. Gatumba is like a little refugee camp that was there in Burundi. I don't really remember which day, but one night the war began again. No one knows...I don't really know the root cause of the war in Burundi, but that's it. Running away, fleeing all the time, leaving our things behind, leaving our documents. We had already looked into going to Malawi... leaving... So the insecure life, I'd say there is no real security. (Gilles) 
Participants reported living in up to four countries prior to arriving in Canada. In most of these situations, the young people lived in refugee camps, often for years, where the war-related suffering and insecurity continued:

The suffering from the refugee camp is not like the war, to shoot people, but you suffer... People....are crying. If you see the budget they are making to eat. They eat only once per day... They sleep without eating...If you don't do something so that you can help yourself you can die of starvation. You're sleeping but...you don't sleep. If the rain comes sometimes in your house. (Boris)

Morally, [the war] affected us...I got to know what is hunger, not having clothes. Everything was like a nightmare...We never ate snails before, but we saw people eating it when we came to the Ivory Coast, and then so my mother said, "Well, this could be food, too." (Tamara)

The above narratives provide a snapshot of the intensity of youths' experiences where war ravaged their livelihoods, families and in multiple ways truncated their childhoods. The participants' poignant stories reveal the continued breach of their rights. Indeed, the obligation to provide "protection and care" to children has been infringed upon repeatedly and violently. As such, one would be tempted to conclude that Article 38 makes no (or little) difference to their lives. However, this conclusion would be limiting given that applying a child rights perspective entails enabling voice to children's testimonies. In listening to their stories we learn about their physical, emotional and environmental realities. It is in light of youth's reflections on their past, that one can begin to understand their views on resettlement.

\section{Youth Perspectives On Resettlement To Québec}

In the following section, we examine youth perspectives on resettlement, keeping in mind that Article 39(4) identifies the obligation to "promote physical and psychological recovery and social reintegration" of children affected by armed conflict. Emerging from the participants' perspectives is a sense that the Québec and Canadian government may largely meet their obligation to provide for basic needs, particularly for those who arrive and receive refugee status. 
Much more difficult has been the provision of the right to psychological recovery and social reintegration, not necessarily because of a lack of services but because of the inadequacies of available services. From the youth, we learn that professionals may be well meaning, but largely ill-equipped to deal with the realities and experiences of war-affected youth, ultimately providing inadequate psycho-social services and programs.

\section{Resettlement and the Enduring Legacy of War}

Before arriving in Québec, the vast majority of participants had little (to no) knowledge of Canadian culture or context. Many arrived in Canada seeking asylum, while others were government-resettled refugees. As these participants explained they had little say to which country they would immigrate, yet the prospect of a better future made them welcome the news:

They didn't give me a choice of country, but I was selected. Maybe a dream came to pass. (Tamara)

It's as if, from my point of view, I can say that it is the UNHCR that gave our file to the Canadian government so that the Canadians can also study what is in it. But it may take time. But Canada said, "Okay, we'll accept these people." If the Canadians or other countries don't accept you, you are still waiting for countries that will accept you. (Gilles)

Upon arriving in Québec, depending upon their highly diverse circumstances, participants reported experiencing a flurry of emotions. We found there was a vast difference in the refugee and asylum-seeking experience depending on the context of their arrival. For some, the arrival was more traumatic, and they experienced fear and loss of dignity:

And so they [immigration] put me in this room...And it was just an empty room with like you know those concrete cinder blocks, just painted...Just a hard bench, and there was nothing else in the room. Maybe a couple of posters. You know, like, "Welcome to Canada" posters. And I remember seeing these posters at all these happy faces of people coming to Canada. And there was this juxtaposition of my misery just sitting in there, 
you know, and thinking to myself, “These guys really don't care." A certain part of my dignity had been lost, because as far as these guys [immigration] are concerned this is just another refugee coming into Canada trying to seek political asylum. (Andy)

[In Sierra Leone] I never knew where the ship was going. I just saw the ship...we boarded the vessel [illegally]...we hid in a container. When I think about the way we came here, it makes me cry. Because it was too tough. It's too tough. Only God who saved us from that journey...It really was tough... I arrived at the Montreal seaport. But we never knew where we were... When we arrived [in Montreal immigration] they handcuffed me... I was afraid, for sure... That was my first time in my life [to be handcuffed]...I was afraid, really. (Alexis)

Others experienced joy, happiness, and a sense of good fortune:

I'm doing really well... I have good memories of when I arrived. There, we left ... at the Montreal airport. We saw a ... it is our brother, I can also say, it's...I have a dad... and he's Rwandan, too...Oh, it was great! It was the best present from my father. And it was cold outside. We got used to it eventually. We didn't care. Everyone cried. It was beautiful to see! Yes! (Diego)

When I came here I see it like a miracle. In Canada there are no problems. There's no war; there's no fighting (Boris).

Several participants experienced a 'honeymoon phase' upon arrival to Canada. As evoked by this young person, a feeling of awe dominated, at least temporarily:

When I got here, it was like a shock. Nothing was clear to me. Like, in my mind, I was -I didn't ask myself, where am I going, and when I get there, how will life be? I did not ask myself all those questions. No. It's just like, I fell from heaven. [laughs] Yeah, lucky to come in. That was my wish. My wish to come to Canada. And they said yes. Welcome 
to Canada... If you ask me to describe it I would just use one word and say it was "wonderful." (Jasmine)

While participants had overcome significant wartime challenges and, in many cases, arrived in Canada full of hope and optimism, the legacy of war and displacement in their lives persisted. As these participants explained:

I think that's it, and it creates distrust, I'd say, anger and especially lots of distrust. If it happens, tomorrow, what will happen? You have to, well - be ready for anything. But you also say to yourself, it could be worse. (Kimberly)

I was also traumatized. After [the] genocide, I couldn't sleep. I was traumatized. (Jasmine)

It was a little unsettled. Unsettled. And going from a beautiful reality [before the war] to a reality [in Canada] that... it isn't really right. (Alina)

Participants' narratives highlight several key issues. First, the legacy of war did not simply end when they entered Canada. Participants carried with them the legacy of the past, in all its complexities, bringing forth both the realities of trauma and resilience simultaneously. Second, their arrival to Canada immediately brought with it new challenges, possibilities, and the reality of having to begin a new life in an unknown place. This point is summed up well by this participant:

You're coming from a country where people are suffering. I think it haunts you in a sense. And maybe it even goes back to when I was talking about being a traitor and leaving these people to suffer by themselves, while all the way up here [in Canada]. For a while, that bothered me...But, as well, just for the culture shock of being in this part of the world by myself, right?...I literally had to start from scratch. I was like a little baby. (Andy) 
The legacy of the past, alongside the uncertainty of their future, highlights the vital importance of promoting the physical and/or psychological recovery and social reintegration of young people who have been affected by war, as clearly established in Article 39 of the UNCRC. Given that the governments of Canada and Québec accept these youth as refugees, government bodies have an unequivocal obligation as duty bearers to honour these rights. Moreover, as the next section will demonstrate, participants identified gaps in terms of their psychological needs and well-being, as well as their overall social reintegration. Duty bearers, including teachers and helping professionals, while well-intentioned, are often not well-equipped to honour these rights.

\section{Inadequacies of Reintegration Support in School and from Helping Professionals}

Schools are said to be one of the most influential service systems for young refugees in Canada (Rousseau \& Guzder, 2008) and are often the first point of contact with their new society. The transition to formal schooling may be fraught with challenges due to different learning styles, new systems of rules and the reality that many children have little or no knowledge of French or English. The transition can be made more difficult for war-affected children who, because of the upheaval in their countries of origin, may have little experience of formal schooling. As this participant described, while schooling may be considered necessary it brings immense challenges:

Well, I can say, for me, that it's kind of hard to study... To start, stop, take at least two years without studying, without going to school...Actually, you discourage yourself from going to school. Despite the fact that we're in Canada, we are really obliged to go in order to get a job in Canada. To have something, anything, here in Canada, you have to have a diploma and that's why we are in school, really to seek our fortune. But for a child who has really led the life of a refugee, a little trouble, it depends on the circumstances he experienced. (Gilles)

Participants' past experiences of violence often disrupted or interfered with their ability to study effectively: 
I was able to go to school, but I did not study well as I would be before... Yeah, [the genocide] affects my studies, because, sometimes it's like I remember, my memory goes back [to the genocide]. And then I feel I don't want to study. Sometimes I say, oh, why do I have to study? My father studied, but where is he? Yeah. Sometimes I feel like I don't want to study. (Jasmine)

While the young people were pleased to be able to attend school, once in Canada, their interactions and experiences with peers and teachers sometimes triggered negative wartime memories, as well as a lack of understanding and a trivialization of violence, which made the young people uneasy:

I don't know, here, well [the kids] have not really experienced war. They find it funny... [the kids] watch violent movies and they're like: “Oh, it's cool. There's lots of action"... So maybe if they knew [what war is], they wouldn't say that... [For the teachers], if they were more aware, maybe, that there were people in class who had experienced war, they would pay more attention. Like stopping the comments [from other students] when they go too far. Comments about war. (Alina)

The diversity in lived experiences could easily result in misunderstandings. Comments involving violent imagery - that were intended to be 'jokes' - were interpreted differently by participants:

When we were working, we did practical exercises. One of the people who was in charge there just said one little phrase: "I'll tear your head off if you answer yes or no. I need an explanation!" "Yes," I said. "Wow!" I had to answer yes or no, but he meant it as a joke. But for me, the joke went directly into my brain: "Oh! They're going to rip our heads off! Wow! Oh! It's normal!" Because I experienced things where, like, people's heads were being ripped off. And I said to myself, "That guy too, he could rip our heads off. Wow!" That's what I understood, given the situation I experienced... But for him, ripping off someone's head, he sees it on TV. He has never been involved in anything where people's heads are getting ripped off. Okay, so he thinks it's a joke. But for me it was really hard...So I withdraw a little, and I say to myself, "What's going on here? Where am I? 
Where did I end up?" It took a while before anyone explained all this to me - these things, the circumstances we went through. (Ronaldo)

Participants noted that while teachers at school were well-intentioned, they were often illinformed and unaware of the impact and realities of war. This participant provided an example, highlighting her wish for teachers to be better informed:

For the teachers to be more...to pay more attention, or for them to know more. Because in my French class, there is also a girl from Rwanda. And the teacher said, "We're going to the cinema to watch a Québécois film." And the film talked about the genocide in Rwanda. And the girl cried through the whole film. And in fact there were no resources at that time to help her. Everyone felt bad, and yes, we listened and everything, but it wasn't great. And I'm sure that after, there was no follow-up, there was no one... she didn't meet with anyone. So that's it. The teachers should really be informed about that... if they knew more.... (Alina)

While participants noted that they would have liked to receive psycho-social support, few attempted to reach out for formal sources of help including psychologists or social services. There was disbelief and distrust in the value of this help. One participant explained: "I don't see what someone else can help?" She further stated, "They can help [others], but not me." (Jasmine). Those who did seek the help of a psychologist reported negative experiences, largely because they felt that professionals were unable to provide specialized support. Responses to them and their stories were often inappropriate:

I make an appointment, the first, and I see the psychologist. I tell her my story and we cry and cry and cry. [Both of you?] Yes! I come home and I make another appointment, and we cry and cry. And I said, “Actually, this is exhausting, this therapy.” I don't go back. I think, we met for an hour and a half to cry. So I just never went back. So now, if I go to see a psychologist, I ask myself, "Will he really understand my situation? Will he..." Well, that's it, I wonder. Are they ready to listen? And if they do, will they know how to react or not? I find that sometimes they are... They'll say, "Yes, 
that's normal, that's normal" but what's normal? ... [When I did seek help] I found that they were... well, they normalized everything: "There's no problem." So actually I said to myself, they don't understand. They say, "It's all normal" but... it's not helpful for them to say "Oh, well, it's normal for you to be like this [after experiencing war], it's normal." Or they're not really listening, I find. (Alina)

Participants noted the importance of developing more specialized services for waraffected populations. They felt that increasing psycho-social support was a natural extension of the government's responsibility following their arrival. As this participant explained, dealing with this traumatic past was necessary for their long-term integration:

People who come from war-affected countries I believe [the government] should do something more for them. Because they are people who are already morally not too okay, being they went through so many situations...Yes, so, just give them moral support, talk to them...But the main thing to do is like there is an English saying that if you teach a man how to fish, you feed him for his lifetime. But if you give him a fish, you just feed him for a day. So, it's like welfare. (Tamara)

I think sometimes I have those kind of angers and all that stuff...It probably would have helped to, you know, get some sort of support back then...The person who is coming from a war-torn country... there is absolutely no doubt that [psycho-social help] should literally be forced on them. Just sit down and let us make sure that everything is fine, you know? (Andy)

On the whole, participants' perspectives suggest that the provision of Article 39 is not provided for. A lack of awareness of participants' unique needs, while not intentional, was hurtful, contributing to a feeling of discomfort that complicated rather than eased their recovery process. In the absence of appropriate services and resources, participants sought out alternative solutions, highlighting their agency and capacity. 


\section{Youth Carving Their Own Networks: Active Rights-Holders}

A remarkable finding from the study was that all the young people developed personal networks, whether peers, surrogate families and/or communities, which provided psycho-social support, information, and resources. These informal networks became central to making their way, both upon arrival and in the longer-term realities of resettlement. Participants spoke emphatically about the critical role played by the informal system. For some, this informal support consisted of those from their own community, who shared their experiences:

And those people, refugees from my country who were there, they would help me, like -you know, when you get here, they ask you a lot of things, like documents to bring. I didn't know where to go, like how to get there. Like, they would help me take a metro, because you know, like, I didn't know the metro. So they would help me, take me there, how to take pictures. There is the Rwandan community. Like, I got to know people from the community and -- we talk. Like, they help me know some things that I don't know. Yeah, I think the Rwandan community. That's where I get a lot of things. (Jasmine)

For me, it is good is - all Nepali, they're going to help. That is very good. Even when they are [busy], they're going to help us. For Nepali, it's that habit, it's very good. And sharing each other is very good...Most of the time - everyone Nepali, they try to help each other, and they sharing all thing, I mean, like, if - if I have something for eat, and my friend have not, so I'm going to share. We're going to eat half-half. (Katrina)

Others identified more broadly the help from the community, whether from other refugees and/or asylum-seekers or from the church:

But fortunately what happens is that the people who leave just before - it was really such a community. You get connected through people who were at the [YMCA] just before you. Like say you arrive and there's this overlap of people. And they were just so help for. They will, and it will say, "Hey, my landlord is looking for." So, it was always easy. People were always connected. It was incredible the network that was going on. (Andy) 
Through the church I found lots of people who helped me out of the goodness of their hearts, who really supported me in the process, who showed me the city, explained to me how things work in Québec. (Ronaldo)

Others spoke about finding support from surrogate families:

And then there are many individuals. Families who have made me a part of their family. The reason I'm going back to Zimbabwe now is because of a good friend of mine who I met at camp when we were working together. We became really close. He is one of my best friends. As a birthday present last year he bought me a ticket to go back to Zimbabwe, which I'll be doing this year in December. I have also my friend Joseph, who I have known for almost as long as I've been here. His family has been very supportive of me. I call his mother Mom and a call his father Dad because that's how close I am to them. It's like an African thing when the people who contribute to your upbringing, you can't keep calling them by name or Mr. or Mrs., forever. They take on a role which is closer because the old adage of "it takes a village to raise a child" stands strong. And so they are the village, therefore, they are my family because they raised me so, yeah. (Andy)

These short narratives demonstrate the participants' agency and capacity to contribute to their own healthy development and healing. Faced with the realities of post-war hardship and the challenges of adapting to a new culture, young people were active in seeking alternative support systems to deal with the psychological aspect of their recovery. As this participant (Andy) stated, "I didn't sit down and expect to be spoon-fed...I did go and get that support through other people, through other organizations."

If our sample suggests that informal support systems took the place of more formalized sources of support because they were inappropriate or were deliberately avoided, what are the implications for children's rights? Simply concluding that war-affected young people's rights are being unmet and breached would be simplistic and unwanted given the broader value of the UNCRC as a framework to provide a springboard for right-holders and their advocates to hold government and other institutions accountable (Swadener, Lundy, Habashi, Blanchet-Cohen, 
2013). Below, we propose areas for consideration for further actualizing a children's rights perspective based on the findings from our study.

\section{Implications For Enhancing Children's Rights}

This study contributes to understanding the wartime, flight and resettlement experiences of war-affected refugees and asylum-seekers. Youth perspectives in this study point to the inadequate provision of Articles 38 and 39.

On the whole, it is without question that these children and youth displaced from war zones endured a tremendous amount of trauma and adversity that have had long-term psychosocial impacts. Despite their young age (between the ages of 11 and 22 upon their arrival), participants arrived in Canada and had already lived what could be considered a lifetime. They had escaped and survived profound violence, experienced the painful loss of family members, as well as their country of origin, and as a result of displacement, they had lived and adapted to numerous cultures and contexts. Prior to their arrival to Canada, some participants had already lived independently, sometimes acting as caregivers to younger siblings. Upon arrival to Canada, participants appreciated the provision of basic services including temporary shelter food and social assistance. However, thereafter, participants found the formal services and resources inadequate in meeting their psychological needs. More meaningful to the young people was the support they found from the informal networks.

One key implication of this study is therefore to rethink how the formal system provides support for young people affected by war. Our study suggests that perhaps some answers lie in better understanding what works in the informal system; how can the features and skills that young people identify so favorably inform the formal system to create an "environment which fosters the health, self-respect and dignity of the child" as cited in Article 39? Indeed, the harsh reality of children affected by war calls into question conventional training and one-on-one approaches to counseling of young people who have experienced serious adversity, lending support to the increased criticism of Western biomedical approaches (Summerfield, 1999). Our study points to the need for professionals to acknowledge young people's harsh past, and to create environments where they feel their stories can respectfully be listened to, as well as the value of collective approaches to healing which may involve peers and community members who have experienced similar events or not, but are empathetic and available to invest in the 
relationship-building that is so critical to these young people's recovery and reintegration (Wessell, 2009). An important follow-up to this study is to examine the policies and programs in place in Québec that specifically support war-affected children and how these compare with children's experiences as reported in the study.

A second and related implication is the importance of involving young people who have experienced war in the design and evaluation of services and programs. Young people's right to participation has been established by the UNCRC as an overarching guiding principle, and explicitly stated in Article 12. Yet young people are rarely included in the creation and monitoring of protection policies and program (Checkoway, 2011). Recognition of participation is a specific shift with respect to war-affected children given the predominant emphasis on children's maladaptive, antisocial behaviour in the aftermath of war, as well as negative physical and mental health outcomes in research and programming (Derluyn, Broekaert \& Schuyten, 2008). UNICEF (2009) has stated, however, that: "young people should be seen....as survivors and active participants in creating solutions, not just as victims or problems" (p. 6). Our research supports the point made by Myers \& Bourdillon (2012) that "to ensure that protective policies and programs are beneficial to children, it is necessary to consult them to take their opinions seriously" (p. 617). In involving young people, one can hope to create services and programs that war-affected young people will actually use. Indeed, further research is warranted in establishing how best to involve young people. While there is great value and increased knowledge on ways of working with younger children, our study suggests that youth who have some distance from their immediate transition can perhaps more easily critically inform program design and implementation. The younger people interviewed were often so thankful to be in Canada that they were not in a position to be critical.

The final recommendation is a call for increase research with young people affected by war. While this study reports on the rich findings from the interviews and focus groups, a next step is to involve young people in other forms of research that allows them to explore and develop solutions to respond to the current inadequacy of the system, and breach of their rights as provided by the UNCRC. As shown in this study, war-affected young people are 'active rights holders.' Scholarship can contribute to this power by offering a space for their views and validating their perspectives in ways that inform policy and program, and that does not 
inadvertently reinforce popular discourses of these children and youth as inherently troubled, victimized, and perpetually "at risk."

Long-time child advocate Graça Machel has noted: "war violates every right of the child...the impact of conflict on children is everyone's responsibility, and it must be everyone's concern" (UNICEF, 2009: v, 3). What is clear is that this population of children and youth within the context of Québec and Canada deserve greater attention and ensuing action. Failing to systematically address children's needs may result in future challenges to Québec and Canadian society in the education, employment, and health systems. Understanding, through research, the complexity of children's needs and experiences, alongside the development of appropriate services, can act as a preventive measure, and build on existing individual and community strengths. International migration stemming from war has been increasing (UNHCR, 2009) and will continue to impact Québec and Canadian society. This underscores the continued importance of exploring the rights and realities of war-affected children and youth.

\section{References}

American Psychological Association. (2010). Resilience and recovery after war: Refugee children and families in the United States. Washington, DC: Author.

Ben-Arieh, A. (2008). The Child Indicators Movement: Past, Present, and Future. Child Indicators Research Journal, 1, 3-16.

Betancourt, T.S., Brennan, R., Rubin-Smith, J., Fitzmaurice, R., Gilman, S.E. (2010). Sierra Leone's former child soldiers: a longitudinal study of risk, protective factors, and mental health. Journal of the American Academy of Child \& Adolescent Psychiatry, 49(6), 606615.

Boyden, J., \& De Berry, J. (2004). Children and Youth on the Front Line. Oxford: Berghan Books.

Blanchet-Cohen, N. (2013). Researching violence with conflict-affected young people: context and process. Child Indicators Research. Advance online publication. doi: 10.1007/s12187013-9208-4 
Checkoway, B. (2011). What is youth participation? Children and Youth Services Review, 33(2), 340-345.

Denov, M. and Bryan, C. (2010). Unaccompanied Refugee Children in Canada: Experiences of Flight and Resettlement. Canadian Social Work: Special Issue on the Settlement and Integration of Newcomers to Canada, 12 (1), 67-75.

Denov, M. \& Bryan, C. (2012). Tactical Maneuvering and Calculated Risks: Independent Child Migrants and the Complex Terrain of Flight. New Directions for Child and Adolescent Development, 136, 13-27.

Denov, M. (2010). Child Soldiers: Sierra Leone's Revolutionary United Front. Cambridge: Cambridge University Press.

Derluyn, I., Broekaert, E., \& Schuyten, G. (2008). Emotional and behavioural problems in migrant adolescents in Belgium. European Child and Adolescent Psychiatry, 17(1), 54-62.

Di Tomasso, T. (2010). Approaches to Counselling Resettled Refugee and Asylum Seeker Survivors of Organized Violence. International Journal of Child, Youth and Family Studies, 1(3/4), 244-264. Retrieved from http://journals.uvic.ca/index.php/ijcyfs/article/view/2086.

Downe, P.J. (2001). Playing with names: How children create identities of self in anthropological research. Anthropologica, 43(2), 165-177.

Glaser, B. \& Strauss, A. (1967). The discovery of grounded theory. Chicago: Aldine Publishing. Halcón, L., Robertson, C., and Savik, K. (2004). Trauma and coping in Somali and Oromo refugee youth. Journal of Adolescent Health, 35(1),17-25.

Hart, J. (Ed.). (2008). Years of conflict. Adolescence, political violence and displacement. New York: Berghan Book.

Liebel, M. (2012). Children's rights from below. Cross-cultural perspectives. New York: Palgrave Macmillan.

McCloskey, L., \& Southwick, K. (1996). Psychosocial problems in refugee children exposed to war. Pediatrics, 97(3), 394-97.

Ministère de 1'Immigration et des Communautés culturelles. (2009). Présence en 2009 des immigrants admis au Québec de 1998 à 2007. Gouvernement du Québec. 
Myers, M., \& Bourdillon, M. (2012). Concluding reflections: how might we really protect children? Development in Practice, 22(4), 613-620.

Rousseau, C., \& Guzder, J. (2008). School-based prevention programs for refugee children. Child and Adolescent Psychiatric Clinics of North America, 17(3), 533-49.

Summerfield, D. (1999). A critique of seven assumptions behind psychological trauma programmes in war-affected areas. Social Science and Medicine, 48 (10), 1449-1462.

Swadener, B., Lundy, L., Habashi, J., \& Blanchet-Cohen, N. (Eds.). (2013). Children's Rights in Education: International Perspectives. New York, NY: Peter Lang.

UNHCR. (2009). UNHCR Global Resettlement Statistical Report. Washington, DC: Resettlement Service, Division of International Protection Services.

UNICEF. (2009). Machel Study 10-year Strategic Review: Children and Conflict in a Changing World. Retrieved from http://www.unicef.org/publications/index_49985.html

Vandenhole, W., Parmentier, S., \& Derluyn, I. (2011). International law on children and armed conflict: the interface between various normative frameworks. Human Rights and International Legal Discourse, 5(2), 2-13.

Wessells, M. (2009). What we are learning about protecting children in the community? An inter-agency review of the evidence on community-based child protection mechanisms in humanitarian and development Fund. Unicef Report. Retrieved from http://www.unicef.org/wcaro/english/What_We_Are_Learning_About_Protecting_Childre n_in_the_Community_Full_Report.pdf 